\title{
A Survey of Seasonal Gastrointestinal Parasitic Infections in Donkeys from a Semiarid Sub-Saharan Region, Sudan
}

\author{
Ahmed Abdurhman Ismail, ${ }^{1}$ Nasredin Khogali Ahmed, ${ }^{2}$ Ahmed Elhag Bashar, ${ }^{3}$ \\ Hisham Ismail Seri, ${ }^{4}$ El Tigani Ahmed El Tigani-Asil, ${ }^{1,5}$ and Adam Dawoud Abakar ${ }^{6}$ \\ ${ }^{1}$ Department of Pathology, Faculty of Veterinary Science, University of Nyala, P.O. Box 155, Nyala, Sudan \\ ${ }^{2}$ Directorate of Animal Health, State Ministry of Agriculture and Animal Resources, P.O. Box 155, Nyala, South Darfur, Sudan \\ ${ }^{3}$ Department of Microbiology and Parasitology, Faculty of Veterinary Science, University of Nyala, P.O. Box 155, Nyala, Sudan \\ ${ }^{4}$ College of Veterinary Medicine, Sudan University of Science and Technology, Khartoum, Sudan \\ ${ }^{5}$ Faculty of Agriculture and Veterinary Medicine, Qassim University, P.O. Box 6622, Buraidah 51452, Saudi Arabia \\ ${ }^{6}$ Department of Medical Parasitology, Faculty of Medical Laboratory Sciences, University of Gezira, P.O. Box 20, Wadmedani, Sudan
}

Correspondence should be addressed to El Tigani Ahmed El Tigani-Asil; asiltiganiz@gmail.com

Received 1 November 2015; Accepted 3 March 2016

Academic Editor: Alexander Rodriguez-Palacios

Copyright ( $) 2016$ Ahmed Abdurhman Ismail et al. This is an open access article distributed under the Creative Commons Attribution License, which permits unrestricted use, distribution, and reproduction in any medium, provided the original work is properly cited.

\begin{abstract}
Out of 92 donkeys examined for gastrointestinal parasites, 90 animals were found infected by one or more gastrointestinal parasites with an overall prevalence rate of $97.78 \%$. The distributions of the recovered parasites in the different parts of the body were as follows: stomach, $92.4 \%$, small intestine, $19.6 \%$, caecum, $88 \%$, colon, $80.4 \%$, rectum, $73.9 \%$, and cranial mesenteric artery, $64.1 \%$. A significant difference was found between mean parasite counts and seasons. Hot wet season had higher mean parasites count $(5411.5 \pm 1694.4)$ in comparison with hot dry $(1795.9 \pm 399.6)$ and cool dry (1719.9 \pm 522.4$)$ seasons. Although there was no significant difference between age and mean parasite count, animals more than four years old had high mean count (3361.3 \pm 921.8$)$ in comparison with $2330 \pm 744.3$ and $2030.2 \pm 873.1$ for young and adults animals, respectively. No significant positive or negative correlation was found between total parasite counts of infected animals and any of the climatic factors. The parasites identified were Habronema spp. (40.2\%), Trichostrongylus axei (30.4\%), Parascaris equorum (18.5\%), Anoplocephala perfoliata (4.35\%), Gastrodiscus aegyptiacus (8.7\%), large strongyles (84\%), small strongyles (72\%), and Oxyuris equi (1.1\%).
\end{abstract}

\section{Introduction}

The importance of donkeys in the Sudan is unequivocal. The animal provides support and transport at a low cost for urban and rural areas. The donkey has a potential of making valuable contribution to new development strategies such as reconstruction and development programmes in many parts of Sudan especially Darfur region as they diversify source of income in the rural areas. Despite the economic importance of donkeys in the Sudan, little attention has been drawn towards their diseases in general and particularly gastrointestinal parasites. The earliest recognized parasitic disease of donkeys in the Sudan was strongyle infections which have been shown to cause serious losses in affected areas [1, 2]. The report of Hamid et al. [3] from South Darfur has attracted the attention of scientists towards the importance of donkey parasites especially gastrointestinal parasites. A few years later, reports from Khartoum and Nyala provided some information on the distribution of gastrointestinal parasites and other parasitic diseases in the Sudan [4-7]. Nevertheless, the current situation of parasitic disease in other states where the donkey is usually prevalent is rather obscure and deserves some more emphasis. The present study reports on the prevalence of gastrointestinal parasites of donkeys in Nyala, South Darfur State, and identifies the gastrointestinal parasites infesting donkeys in the study area. Furthermore, the study highlights risk factors associated with gastrointestinal parasitic infection. 


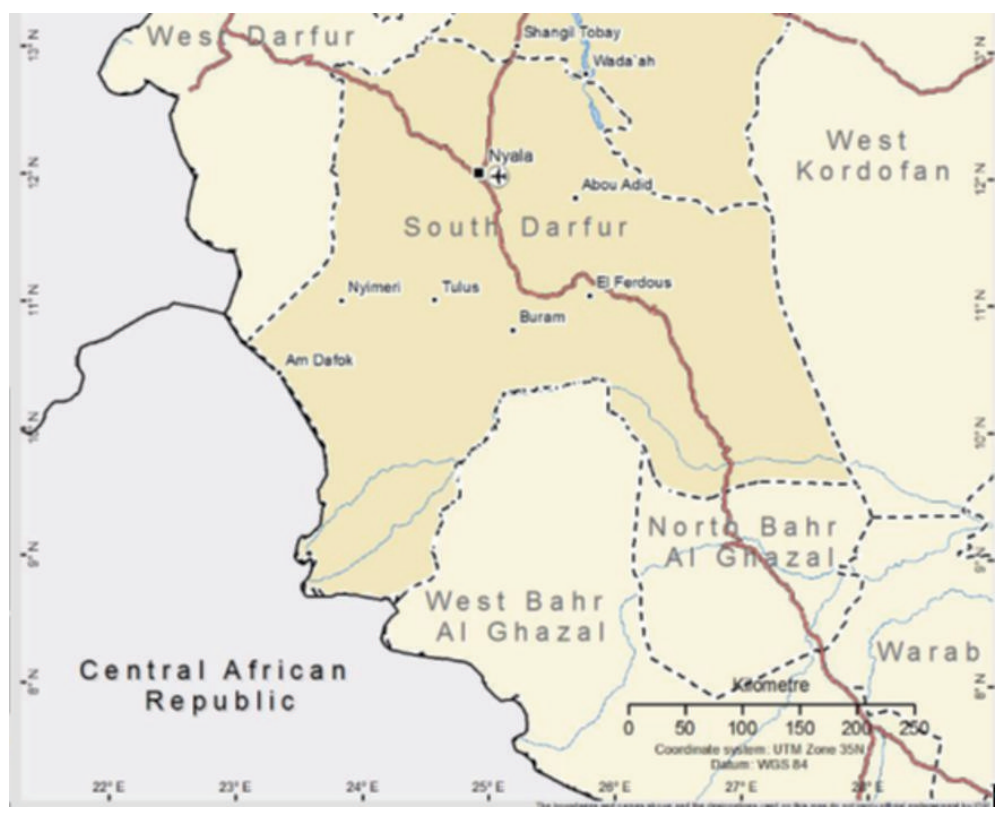

FIGURE 1: Geographical location of the study area, South Darfur State [8].

\section{Materials and Methods}

2.1. Study Area. The present study was conducted at Nyala town, South Darfur State, Sudan. South Darfur State is located in the southwest of Sudan. It covers $139800 \mathrm{~km}^{2}$ between latitude $13-9.30^{\circ}$ north and longitude $27-24.30^{\circ}$ east. The state has common boarders with North Darfur, West Kordofan, Northern Bahr El Ghazal, and West Darfur States. It also shared boarders with Chad and Central Africa Republic [8]. The climate in South Darfur State is savannah type with clay sandy soil in the south, while the north is semidesert with sandy soil. The meteorological annual data of 40 years obtained from Nyala Airport Meteorological Station showed that the mean minimum and maximum temperature are $20.98^{\circ}$ and $35.14^{\circ} \mathrm{C}$. The mean annual relative humidity is $35.58 \%$ and the mean total rainfall is $402 \mathrm{~mm}$. There is a single rainy season, which occurs between June and October, but the bulk of the rainfall takes place during the period of July-September. The area is traversed by several watercourses originating from Jebel Marra Mountains; the natural pasture is dominated by abo-asabei grass (Dactyloctenium aegyptium) with variable proportion of legumes (Figure 1).

2.2. Study Animals. This study involved 92 donkeys. Animals used in this study were purchased from Nyala livestock market and were admitted from different areas in the South Darfur State but most of them came from camps of displaced people. All the animals examined were of common local type and of varying ages (1-13 years) and of both sexes (Figure 2). The majority were adult animals. Considering the husbandry and care practices of donkeys in South Darfur State, the body condition of the animals and their other parasitic faunas suggested that they had rarely received any drug treatment against gastrointestinal parasites.
2.3. Experimental Design. This is a cross-sectional study; the plan of work constituted a 12-month parasitological survey on the donkeys obtained from Nyala livestock market extending from May 2005 to April 2006. The examined animals were acquired at different seasons of the year representing the dry cold season (November-February), dry hot season (MarchJune), and wet hot season (July-October). They were from animals that graze on natural pasture throughout the year. Five to 13 donkeys were examined every month. The intervals between the acquisition of animals and necropsy examination range between 3 and 7 days.

2.4. Postmortem Procedures. From May 2005 to April 2006, 92 donkeys were killed and necropsied at the Faculty of Veterinary Science, University of Nyala. The animals were killed by the jugular vein and carotid artery bleeding after administration of either chloral hydrate or thiopentone sodium as general anesthesia. Every week 1-2 donkeys were sacrificed for postmortem examination for a whole year. The animals were fastened for two days prior to necropsy. The necropsy procedures were done as those previously described [9]. The collected materials from the different parts of the thoracic and abdominal cavities were sieved through $80 \mu \mathrm{m}$ mesh screen, the residues preserved in $10 \%$ formalin. The identification was accomplished by using binocular microscope under 4, 10, and 40x (Olympus microscope, Japan). The classification of nematodes was done using the early description. The identification of the cestodes and the trematodes was done as described by Soulsby [10].

2.5. Statistical Analysis. Data were summarized in terms of prevalence, abundance, and intensity of infection. Differences among prevalence rates in relation to season, age, and type were tested by Duncan test and the differences were 

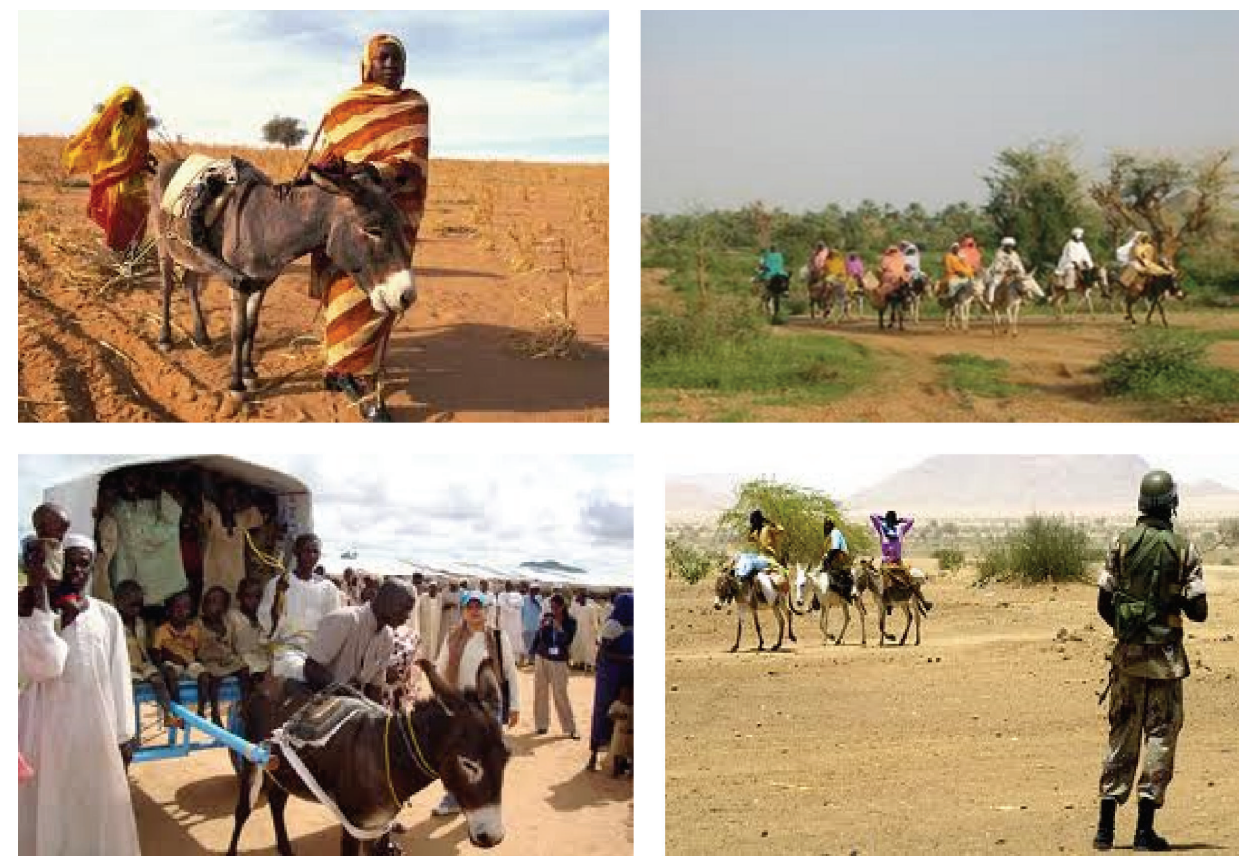

FIGURE 2: Climate and landscape of the study area. Pictures by the authors, 2011.

considered significant when $P<0.05$. Software used was SPSS for Windows, version 14.0.

\section{Results}

The postmortem examination of 92 donkeys for the presence of gastrointestinal parasites showed that 90 animals were infected with one or more parasites. The overall infection rate of identified parasites of donkeys obtained from Nyala livestock market was $97.78 \%$. Almost all animals infected harboured mixed infections. The distributions of the recovered parasites in the different parts of the body were as follows: stomach $(92.4 \%)$, small intestine $(19.6 \%)$, caecum $(88 \%)$, colon $(80.4 \%)$, rectum $(73.9 \%)$, and cranial mesenteric artery (64.1\%). The effect of season on the prevalence rates is shown in Table 1. Although dry cold season gave $100 \%$ prevalence rate, no significant difference was observed between different seasons. The prevalence rate of identified parasites according to age is shown in Table 2. No significant difference was observed between the age groups and the prevalence of infection. Although there was no significant difference between age and mean parasite burdens, animals more than four years old had high mean burdens $(3361.3 \pm 921.8)$ in comparison with $2330 \pm 744.3$ and $2030.2 \pm 873.1$ for young and adult, respectively (Figure 3 ). Moreover, significant difference in mean parasite burdens was found among seasons $(r=$ $\left.0.263^{*}\right)$. Hot wet season had higher mean burdens (5411.5 \pm 1694.9) in comparison with $1795.9 \pm 399.6$ and $1719.9 \pm 522.4$ for hot dry and dry cold seasons, respectively (Figure 4).

The mean total count of parasites recovered from small stomach, small intestine, colon, caecum, and rectum was depicted in Tables 3-5.
TABLE 1: Effect of season on the prevalence of donkey parasite recovered by postmortem examination during May 2005-April 2006.

\begin{tabular}{lccc}
\hline Seasons & $\begin{array}{c}\text { Number of } \\
\text { animals } \\
\text { examined }\end{array}$ & Positive numbers & Prevalence \% \\
\hline Dry cold & 27 & 27 & 100 \\
Hot dry & 37 & 36 & 97.3 \\
Hot wet & 28 & 27 & 96.4 \\
\hline Overall means & 92 & 90 & 97.8 \\
\hline
\end{tabular}

TABLE 2: Prevalence of recovered donkey parasites according to animal age.

\begin{tabular}{lccc}
\hline Ages & $\begin{array}{c}\text { Number of } \\
\text { animals } \\
\text { examined }\end{array}$ & Positive numbers & Prevalence \% \\
\hline 1-2 years & 23 & 22 & 95.7 \\
2.5-4 years & 17 & 17 & 100 \\
$>4$ years & 52 & 51 & 98.1 \\
\hline Overall & 92 & 90 & 97.8 \\
\hline
\end{tabular}

No significant positive or negative correlation was found between total parasitic count in infected animals and any of the climatic factors (Figure 5). The hot wet season is most preferable for development and survival of the recovered parasites. The highest mean total parasitic count was recorded in August while the least mean parasitic count was recorded in March and April (Figure 6). A total of 11 species and one genus of endoparasites were recovered from the donkeys 
TABLE 3: Monthly mean count \pm SEM of parasites recovered from stomach and small intestine of necropsied donkeys.

\begin{tabular}{lcccc}
\hline Months & Habronema spp. & Parascaris equorum & Trichostrongylus axei & Anoplocephala perfoliata \\
\hline January & 0 & $5 \pm 2$ & 0 & 0 \\
February & 0 & $3.7 \pm 1.2$ & 34 & 0 \\
March & 0 & 2 & 2 & 0 \\
April & 0 & 2 & 47 & 0 \\
May & $186.7 \pm 86.7$ & $1.5 \pm 0.5$ & 0 & 0 \\
June & $34 \pm 9.3$ & $4.6 \pm 1.9$ & $40.3 \pm 20.7$ & 1 \\
July & 80 & 0 & $10 \pm 4.7$ & 0 \\
August & $108.9 \pm 33$ & 0 & $38.5 \pm 15.8$ & 0 \\
September & $28.6 \pm 9.8$ & 0 & $43.5 \pm 8.8$ & 1 \\
October & $69.3 \pm 13.9$ & 14 & $11.5 \pm 2.6$ & 2 \\
November & $43.7 \pm 29.4$ & 2 & $3.7 \pm 1.8$ & 2 \\
December & $41.7 \pm 24.2$ & $17.5 \pm 15.5$ & $18 \pm 11$ & $1.5 \pm 19.6$ \\
\hline Overall & $70.1 \pm 12.2$ & $5.7 \pm 1.8$ & $24.3 \pm 4.5$ & \\
\hline
\end{tabular}

TABLE 4: Monthly mean worm count \pm SEM of parasites recovered from caecum of necropsied donkeys.

\begin{tabular}{lccc}
\hline Months & Large strongyle species & Cyathostomum spp. & Gastrodiscus aegyptiacus \\
\hline January & $143.2 \pm 59.6$ & $20.3 \pm 15.4$ & 0 \\
February & $265.3 \pm 62.2$ & $104 \pm 41.7$ & 0 \\
March & $177.6 \pm 73.3$ & $152.5 \pm 77.5$ & 0 \\
April & $152.5 \pm 82.4$ & $24 \pm 16$ & 0 \\
May & $194.9 \pm 70.2$ & $367.7 \pm 155.6$ & 0 \\
June & $373.2 \pm 83.5$ & $1012.7 \pm 611$ & 0 \\
July & $272.6 \pm 159.5$ & $57 \pm 10$ & 1470 \\
August & $705.3 \pm 160.7$ & $368.6 \pm 91.1$ & 0 \\
September & $314.4 \pm 167$ & $72.7 \pm 70.1$ & $45 \pm 33$ \\
October & $314.8 \pm 60.1$ & $38.8 \pm 27.9$ & 5 \\
November & $126.4 \pm 41.9$ & $37.8 \pm 12.8$ & 0 \\
December & $1272.2 \pm 936.5$ & $468.3 \pm 173.6$ & 0 \\
Overall & $357.6 \pm 76.1$ & $293.7 \pm 85.1$ & $391.3 \pm 360$ \\
\hline
\end{tabular}

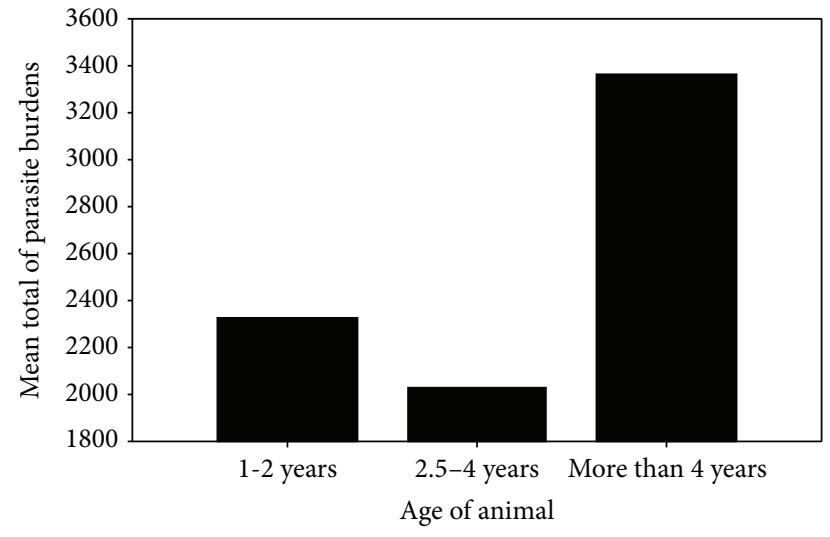

FIGURE 3: Effect of age on the parasitic burden on infected donkeys.

in the current survey. They are Habronema muscae (56\%), Habronema microstoma (37\%), and Habronema megastoma (7\%), Trichostrongylus axei (30.4\%), Parascaris equorum (22.8\%), Anoplocephala perfoliata (15.5), Strongylus vulgaris
(60\%), Strongylus equinus (22\%), and Strongylus edentatus (18\%), cyathostomins spp. (72.3\%), Gastrodiscus aegyptiacus (4.5\%), and Oxyuris equi (1.1\%).

\section{Discussion}

The Darfur region is one of the most heavily populated regions with animals especially equines. However, there are no systemic surveys or records of parasitic diseases occurrences and prevalence. Nonetheless, there have been a few studies that were undertaken in the Darfur region. Previous studies on the evidence of the occurrence of equine gastrointestinal parasites have been provided by S. M. Kheir and H. S. M. Kheir [1], Eisa et al. [11], Hamid et al. [3], and Mohammed [5]. However, their data were based only on analysis of veterinary records, short-period abattoirs surveys, or fecal egg count from clinical cases brought for treatment at the veterinary educational hospitals. Donkey and other domestic animals are known to play a major role in disease transmission in Sudan in general and the study area in particular $[6,7,12]$. It is worth mentioning that human 
TABLE 5: Monthly mean worm count \pm SEM of parasites recovered from colon of necropsied donkeys.

\begin{tabular}{lccc}
\hline Months & Large strongyle species & Cyathostomum spp. & Gastrodiscus aegyptiacus \\
\hline January & $144.3 \pm 33.6$ & $241.3 \pm 101.8$ & 0 \\
February & $463.4 \pm 147.3$ & $1366.7 \pm 574.7$ & 0 \\
March & $160 \pm 73.8$ & $173.5 \pm 112.9$ & 0 \\
April & $170.8 \pm 63.8$ & $335 \pm 118.6$ & 0 \\
May & $410.2 \pm 221.6$ & $2357.6 \pm 1012.7$ & 9 \\
June & $1073 \pm 934.6$ & $1153.9 \pm 504.7$ & 2460 \\
July & $272.7 \pm 189$ & $620 \pm 580$ & 2350 \\
August & $4106.6 \pm 2579.2$ & $5768.5 \pm 3138.7$ & 0 \\
September & $139.6 \pm 49.6$ & $1606.3 \pm 1383$ & $207.7 \pm 147.5$ \\
October & $2412.9 \pm 2084.9$ & $2350.8 \pm 1094.1$ & $5 \pm 2$ \\
November & $163.6 \pm 29.6$ & $1270.8 \pm 651.2$ & 0 \\
December & $1272.2 \pm 936.5$ & $468.3 \pm 173.6$ & 0 \\
Overall & $1038.4 \pm 392.5$ & $1739.1 \pm 394.5$ & $681.3 \pm 380.8$ \\
\hline
\end{tabular}

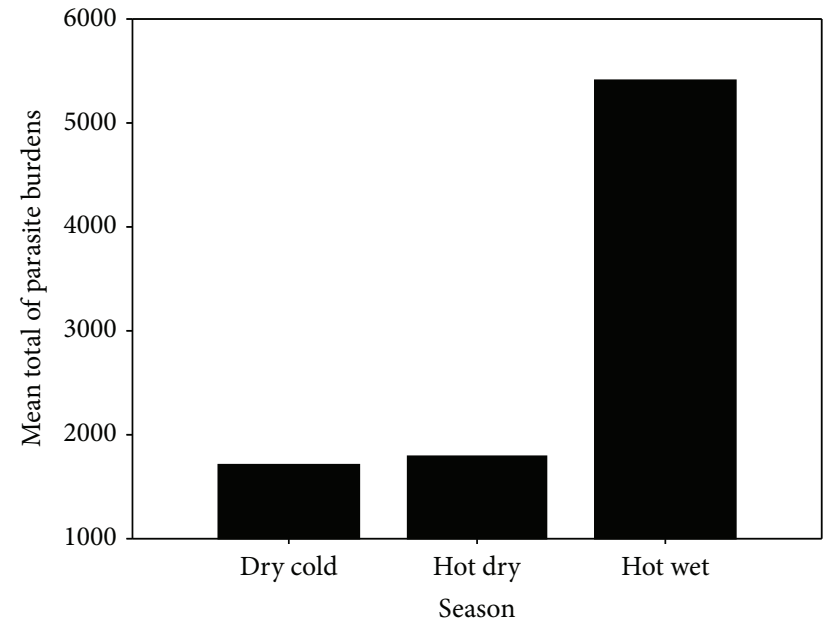

FIgURE 4: Seasonal prevalence of parasite burdens recorded from infected donkeys.

domesticated animals interphase reactions also contributed to maintain some bacterial infections [13] and viral infections [11] worldwide. The current study supported the previous observations on equine gastrointestinal infections in this area and further determined the magnitude of worm burden in apparently healthy donkeys by providing further information on their seasonal prevalence and the influence of the external environment on both the worm species composition and abundance on the host over 12 consecutive months in Nyala, South Darfur State.

The present study established that donkeys in South Darfur State harboured a high rate of gastrointestinal parasites throughout the year; only two animals were found free from internal parasites. This may be attributed to exposure of those animals to previous administration of anthelmintics drugs; 90 animals were positive. Mixed infections were detected in (97.7\%) of the donkeys examined. This is a very high rate compared to the work of Ayele et al. [14], or S. M. Kheir and H. S. M. Kheir [1]; this may be attributed to the different

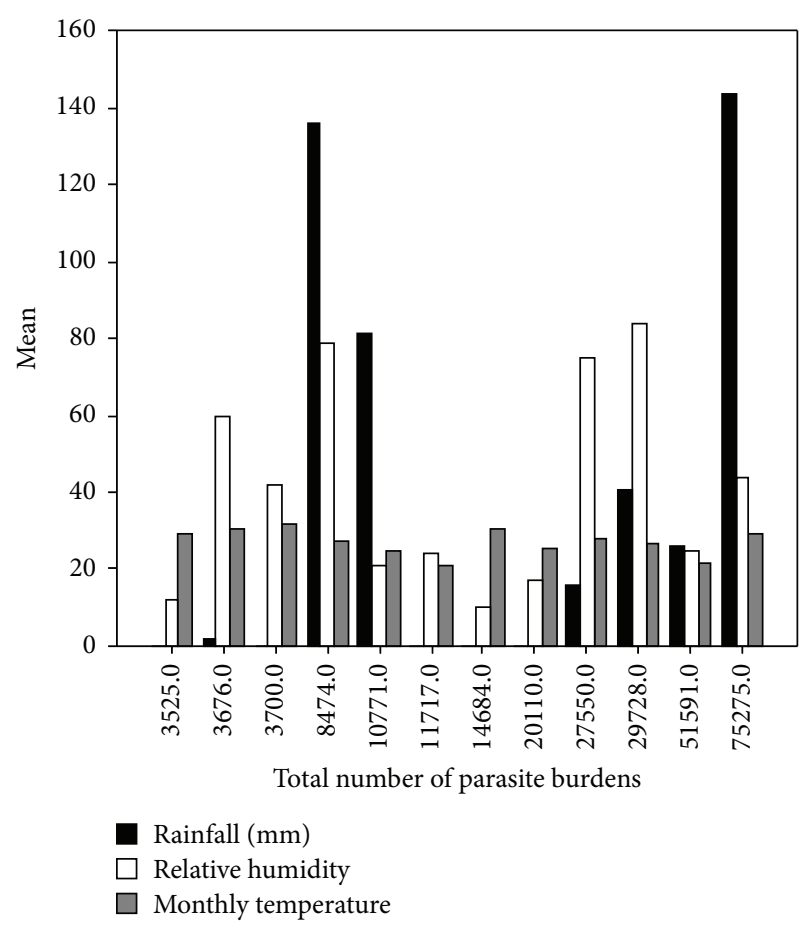

FIGURE 5: Effect of climatic factors on the internal parasitic burdens recovered from examined donkeys.

methods that have been adopted; necropsy always gives a complete epidemiological picture. The high infection rate of parasitic helminthes affecting donkeys reported here might be associated with lack of anthelmintics intervention or might be due to mixed grazing and overcrowding which facilitate contamination between the different animals.

The overall prevalence of Habronema spp. was $40.21 \%$. August recorded a higher mean number of worm burdens and $(100 \%)$ prevalence. This could be attributed to adequate moisture and appropriate temperature that are favourable for both survival and propagation of the parasite and vectors as well. The identification of this parasite to species level 


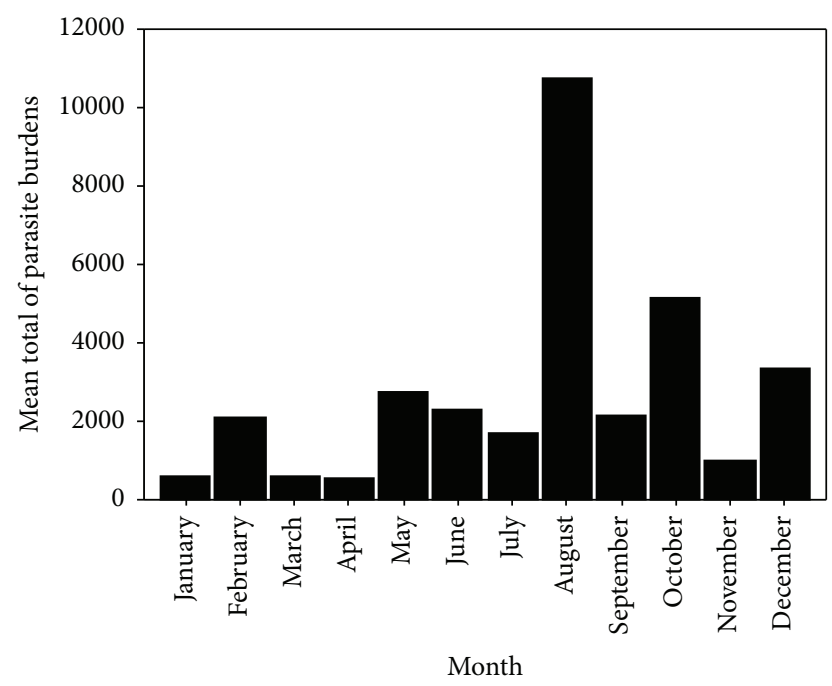

FIGURE 6: Monthly prevalence of parasite count among examined donkeys.

indicated that Habronema muscae is dominant over other species. Similar result has been reported [15]. The intensity of infection with spirurids in the present work was similar to those reported in other equids from South Africa [16] and North Africa.

The prevalence of Trichostrongylus axei reported in this study was $64 \%$; this finding is in agreement with the work of Feseha and Aweke [17] which reported $100 \%$ prevalence in donkeys of Ethiopia and Pandey et al. [18] who reported 93.5\% in Morocco. The prevalence of Trichostrongylus axei reported here was very high when compared to the work of Seri et al. [4] in Sudanese donkey or Lyons et al. [19] in USA. This could be attributed to different methods of diagnosis and species of animal involved. These authors utilized fecal examination, while the current research depended solely on postmortem technique.

The prevalence of Parascaris equorum reported from this survey was $19.6 \%$, which is in accordance with results stated by Yoseph et al. [20] and Fikru et al. [21] who gave 15.7\% and $17.3 \%$ prevalence rates, respectively. Infection of donkeys with Parascaris equorum reported here is relatively high when compared to the work of Seri et al. [4] which reported that the prevalence rate of Parascaris equorum was $10.7 \%$ in the donkeys of Khartoum State and S. M. Kheir and H. S. M. Kheir [1] who found 6.6\% in Nyala and 6.8\% at Bahr El Arab by coprological examination, while, in Kenya, Mukhwana obtained $20.7 \%$ almost similar results [22]. The result of the current survey was very low when compared to the work of Feseha et al. [23] which reported 33\% in Ethiopia and Garber [24] who found that $72 \%$ of examined donkeys in Chad were infested with Parascaris equorum; similarly, Abdelkarim [25] stated that the prevalence rate of the parasites among donkeys of Morocco is $37 \%$.

The level of Parascaris equorum infection during the rainy season had a significant difference compared to the other seasons; this could be because of the adverse conditions prevailing during the hot season. Soulsby [10] stated that hotness dry conditions and direct sunlight kill the eggs in few weeks. Clayton [26] showed that a minimum of 80-83 days are required for newly laid eggs of Parascaris equorum to reach maturity and appear in small intestine so mature Parascaris is unexpected to be seen in the intestine at least at the beginning of the rainy season.

Prevalence rate of Anoplocephala perfoliata (3.3\%) recorded in the present study is relatively low compared to the results of Tolliver et al. [27] which reported 17\% from 513 horses in Kentucky. In some geographical areas like USA and Brazil, a necropsy examination showed a prevalence of infection as high as $60 \%[28,29]$. This low prevalence could be due to seasonality of oribatid mites vector [10].

The prevalence of small strongyles (cyathostomins) reported here was in accordance with findings of Abdelkarim [25] and Feseha et al. [23]. This result was relatively higher than the one reported by Mukhwana [22]. These nematodes are the most common helminthes parasites of equines and can cause considerable morbidity and mortality [30]. Infections with these species of cyathostomins have been recorded in horses, donkeys, and zebra worldwide [31, 32]. Research activities on these nematodes are high because larval cyathostominosis is a serious syndrome that leads to fatal severe colitis. Moreover, resistance to anthelmintics within cyathostomins has been reported widely. Therefore, adoption of accurate diagnostic methods for identification of small strongyles in the study area is highly recommended.

Strongyles infection was correlated with very high prevalence rate, $88 \%$, in comparison to previous reports $[4,33,34]$. The present study confirmed that strongyle infestation was significantly higher in the rainy season of the year. This result was in accordance with the work of Yoseph et al. [20], Mulate [35], and Fikru et al. [21] which indicated that fecal egg count began to rise to severe levels during the wet period of the year. From this seasonal variation of strongyle infestation, a treatment schedule could be proposed. A treatment can be given at the end of the rainy season. At this time, the animals are well nourished and may harbour a large number of parasites without being seriously affected. Eliminating of these parasites will improve the adaptation of the animals to the harsh dry season conditions. Another treatment can be prescribed at the end of the dry season. This treatment reduces infestation of pasture at the first rainfall by residual parasites.

The lower prevalence rate (4.3\%) of Gastrodiscus aegyptiacus reported in the current study might be due to adverse ecological conditions for development of the intermediate host snail, Bulinus forskalii, which need permanent humidity, water marshes, dams, and dampness [10]. The three positive cases found in this study mostly originated from migratory nomads that spend their summer season at Bahr El Arab where the ecological conditions are favourable for the intermediate host of Gastrodiscus aegyptiacus. Gastrodiscus aegyptiacus is more prevalent in the colon than the caecum (1:15); accordingly, it could be said that the parasite favours colon of the donkey compared to the caecum.

The prevalence of Oxyuris equi reported here is very low when compared to the findings of Tolliver et al. [27] and Yoseph et al. [20]. The low prevalence rate in this study might 
be due to the effect of relative high temperature in the study area that desiccates the highly susceptible Oxyuris equi eggs.

In conclusion, donkeys in South Darfur, most of them coming from camps of displaced people, are highly affected by a wide range of gastrointestinal parasites that are prevailing throughout the year. It seems that environmental conditions are favourable for both larval and adult stages, which lead to parasitic burden.

\section{Competing Interests}

The authors declare that they have no competing interests.

\section{References}

[1] S. M. Kheir and H. S. M. Kheir, "Gastrointestinal nematodes of equines in the Southern Darfur State of the Sudan," The Sudan Journal of Veterinary Science and Animal Husbandry, vol. 3, pp. 53-57, 1981.

[2] N. I. El Dirdiri, H. Abu Damir, and A. A. Wahbi, "Disease incidence in donkeys (Equus asinus asinus) with emphasis on Strongyle infection," Acta Veterinaria Belgrade, vol. 36, pp. 313320, 1986.

[3] M. E. Hamid, F. Y. Ali, A. Fadllala, and A. D. Abakar, "Records of clinical cases presented to Nyala Veterinary Teaching Hospital (1993-1996)," The Sudan Journal of Veterinary Science and Animal Husbandry, vol. 37, no. 1-2, pp. 114-120, 1998.

[4] H. I. Seri, T. Hassan, M. M. Salih, and A. D. Abakar, "A survey of gastrointestinal nematode of donkeys (Equus asinus) in Khartoum State Sudan," Journal of Animal and Veterinary Advances, vol. 3, no. 11, pp. 736-739, 2004.

[5] S. E. Mohammed, Clinical and pharmacological investigation of a benzimidazole anthelmintic against donkeys' worm infestation [M.S. thesis], University of Khartoum, Khartoum, Sudan, 2009.

[6] A. D. Abakar, N. A. Khogali, A. E. Bashar, H. I. Seri, A. T. Tigani, and A. A. Abdalmalaik, "Prevalence of Strongylus vulgaris in the mesenteric artery of donkey from Nyala, South Darfur State, Sudan," Research Journal of Parasitology, vol. 8, no. 2, pp. 71-75, 2013.

[7] A. D. Abakar, I. E. Elmahdi, A. E. Abedelmoniem et al., "Romig, Thomas: experimental infection of dogs with E. canadensis (G6) of camel and cattle origin in Nyala, South Darfur State, Sudan," in Proceedings of the 25th International Congress of Echinococcosis, Friendship Hall, pp. 24-27, Khartoum, Sudan, November 2013.

[8] DSSD, "Directorate of survey South Darfur State, Sudan," Annual Report, 2011.

[9] R. K. Reinecke and D. J. Le Roux, "Anthelmintic activity of mebendazole in equines," Journal of the South African Veterinary Association, vol. 43, no. 3, pp. 287-294, 1972.

[10] E. J. L. Soulsby, “The morphology of filariform worms diesing (1941)," in Helminths, Arthropods and Protozoa of Domesticated Animals, Bailliere Tindall, Philadelphia, Pa, USA, 7th edition, 1982.

[11] A. M. Eisa, A. E. S. Elbadawy, M. B. A. Saad, A. M. Ibrahim, and A. Y. El Gezuli, "Check list first records of helminth parasite of domestic and wild animals reported in the Sudan during the period 1902-1979," The Sudan Journal of Veterinary Research, vol. 1, pp. 55-63, 1979.

[12] I. E. Elmahdi, A. E. Abedelmoniem, A. A. Abd Almalaik et al., "A molecular survey for genotyping of Echinococcus species in Sudan," in Proceedings of the 25th International Congress of Echinococcosis, Khartoum, Sudan, November 2013.

[13] A. Rodriguez-Palacios, T. Barman, and J. T. LeJeune, "Threeweek summer period prevalence of Clostridium difficile in farm animals in a temperate region of the United States (Ohio)," Canadian Veterinary Journal, vol. 55, no. 8, pp. 786-789, 2014.

[14] G. Ayele, G. Feseha, E. Bojia, and A. Joe, "Prevalence of gastro-intestinal parasites of donkeys in Dugda Bora District, Ethiopia," Livestock Research for Rural Development, vol. 18, no. 10,2006

[15] V. S. Pandey and M. Eysker, "Parasites of the stomach in donkeys of the highveld of Zimbabwe," Veterinary Quarterly, vol. 10, no. 4, pp. 246-248, 1988.

[16] R. C. Scialdo, R. K. Reinecke, and V. De Vos, "Seasonal incidence of helminths in the Burchell's zebra.," Onderstepoort Journal of Veterinary Research, vol. 49, no. 2, pp. 127-130, 1982.

[17] G. Feseha and T. Aweke, Donkeys in North Gondar: SocioEconomic Importance and Management and Health Constraints, Final Year Paper, Faculty of Veterinary Medicine, Addis Ababa University, Addis Ababa, Ethiopia, 1995.

[18] V. S. Pandey, H. Ouhelli, and A. Verhulst, "Epidemiological observations on stomach worms of donkeys in Morocco," Veterinary Research Communications, vol. 16, no. 4, pp. 273-279, 1992.

[19] E. T. Lyons, S. C. Tolliver, J. H. Drudge, T. W. Swerczek, and M. W. Crowe, "Common internal parasites found in the stomach, large intestine and cranial mesenteric artery of thoroughbred in Kentucky at necropsy (1985-1986)," American Journal of Veterinary Research, vol. 48, no. 2, pp. 268-273, 1987.

[20] S. Yoseph, G. Fesha, and W. Abebe, "Survey on helminsosis of equine in wonche Ethiopia," Journal of the Veterinary Association, vol. 5, pp. 47-61, 2001.

[21] R. Fikru, D. Reta, and M. Bizunesh, "Prevalence of equine gastrointestinal parasites in Western highlands of Oromia," Bulletin of Animal Health and Production in Africa, vol. 53, no. 3, pp. 161-166, 2005.

[22] E. J. Mukhwana, "Helminth parasites of donkeys (Equus asinus) Borchells Zebra (Equus brochelli) and Camels (Camelues dromedaries) in selected area of Northern Kenya," in Proceedings of the Colloquium on Working Equine, M. Bakkoury and R. A. Prentis, Eds., pp. 45-50, Institut Agronomique et Vétérinaire Hassan II, Rabat, Morocco, 1994.

[23] G. Feseha, A. A. Mohamed, and J. M. Yilma, "Vermiculer endoparasitism in donkeys of Debre Zeitand Menagescha Ethiopia Strategic treatment with ivermectin and Fenbendazole in donkeys, mule and horses in tropical agricultural devolpment," in Proceedings of Colloquim on Donkeys, Mules and Horse, D. Fielding and R. A. Person, Eds., pp. 150-166, University of Edinburgh Centre for Veterinary Tropical Medicine, London, UK, 1991.

[24] M. Garber, "Heminths et Helminthiasis des equides de la Republique du Tchad," Revue d'Élevage et de Médecine Vétérinaire des Pays Tropicaux, vol. 23, pp. 207-222, 1970.

[25] M. Abdelkarim, Variation seasnnieres des populations vermineuses et gastrophilienne chez les asines de la regiond de Settat (Chaouial) [thèse de doctorat vétérinaire], Institut Agronomique et Vétérinaire Hassan II, Rabat, Morocco, 1991.

[26] H. M. Clayton, "Ascariasis in foals," Veterinary Record, vol. 102, no. 25, pp. 553-556, 1978.

[27] S. C. Tolliver, E. T. Lyons, and J. H. Drudge, "Prevalence of internal parasites in horse in critical tests of activity of 
parasiticides over a 28-year period (1956-1983) in Kentucky," Veterinary Parasitology, vol. 23, no. 3-4, pp. 273-284, 1987.

[28] R. E. Benton and E. T. Lyons, "Survey in central Kentucky for prevalence of Anoplocephala perfoliata in horses at necrospy in 1992," Veterinary Parasitology, vol. 55, no. 1-2, pp. 81-86, 1994.

[29] A. J. Costa, O. F. Barbosa, F. R. Moraes et al., "Comparative efficacy evaluation of moxidectin gel and ivermectin paste against internal parasites of equines in Brazil," Veterinary Parasitology, vol. 80, no. 1, pp. 29-36, 1998.

[30] R. P. Herd, "The changing world of worms: the rise of the cyathostomes and the decline of Strongylus vulgaris," Compendium on Continuing Education for the Practicing Veterinarian, vol. 12, no. 5, pp. 732-736, 1990.

[31] J. R. Lichtenfels, V. A. Kharchenko, R. C. Krecek, and L. M. Gibbons, "An annotated chick list by genus and species of 93 species level name for 51 recognized species of small strongyles (Nematoda strongyloidea cyathostominae) of horses asses and zebras of the world," Veterinary Parasitology, vol. 79, no. 1, pp. 65-79, 1998.

[32] S. Matthee, R. C. Krecek, and L. M. Gibbons, "Cylicocyclus asini n. sp. (Nematoda: Cyathostominae) from donkeys Equus asinus in South Africa," Systematic Parasitology, vol. 51, no. 1, pp. 29-35, 2002.

[33] D. Wells, R. C. Krecek, M. Wells, A. J. Guthrie, and J. C. Lourens, "Helminth levels of working donkeys kept under different management systems in the Moretele 1 district of the NorthWest Province, South Africa," Veterinary Parasitology, vol. 77, no. 2-3, pp. 163-177, 1998.

[34] A. S. Mohammed and A. M. Atta El Mannan, "The gastrointestinal parasites of some domestic animal species in Damazin District, Blue Nile State, Sudan," The Sudan Journal of Veterinary Research, vol. 18, pp. 99-103, 2003.

[35] B. Mulate, "Preliminary study on helminthosis of equines in south and north Wollo zones," Journal of Veterinary Association, vol. 17, pp. 146-161, 2005. 


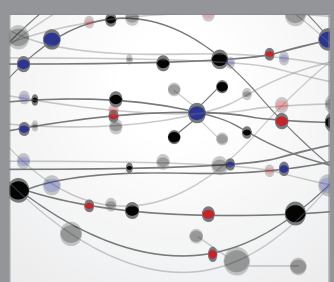

The Scientific World Journal
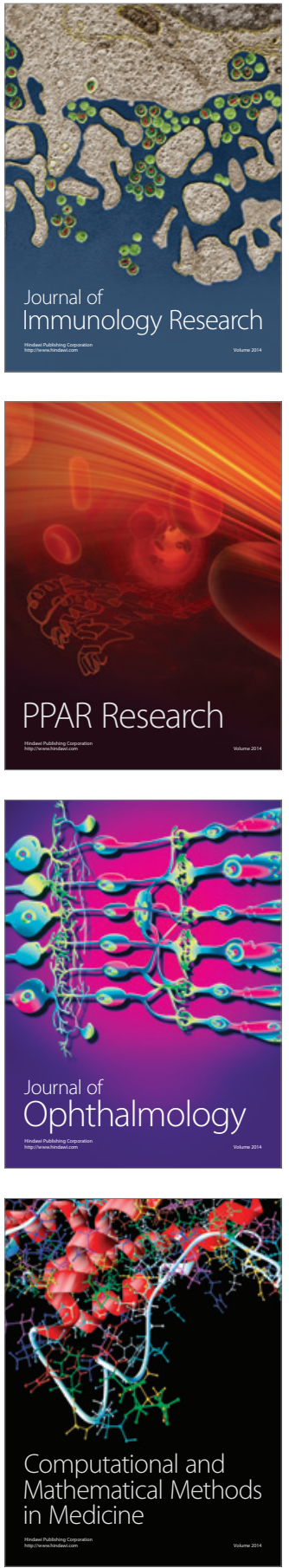

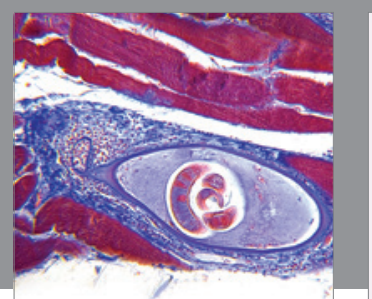

Gastroenterology Research and Practice

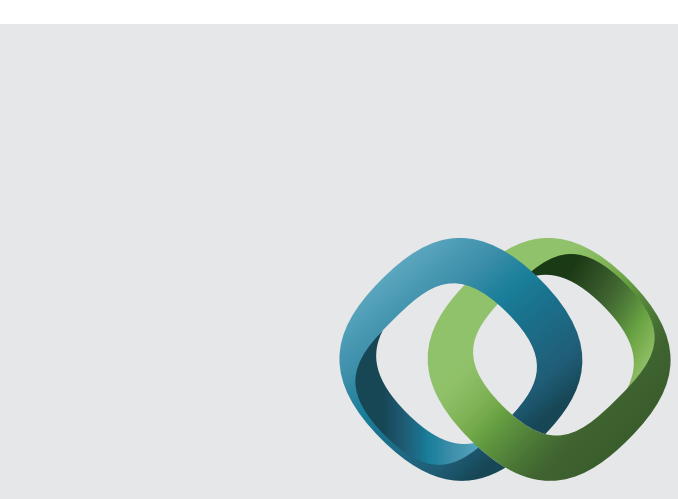

\section{Hindawi}

Submit your manuscripts at

http://www.hindawi.com
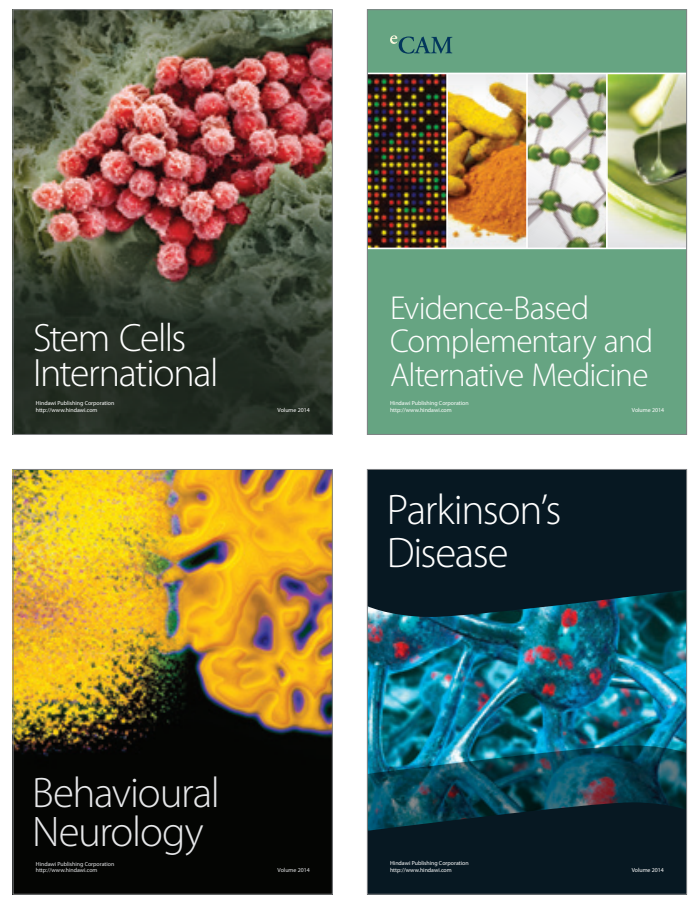
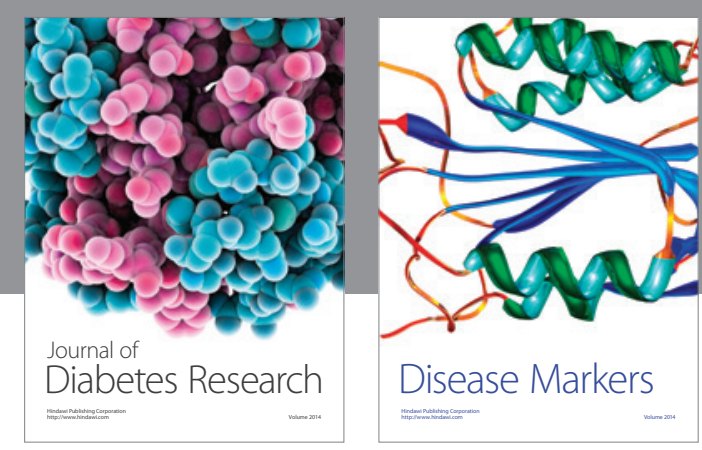

Disease Markers
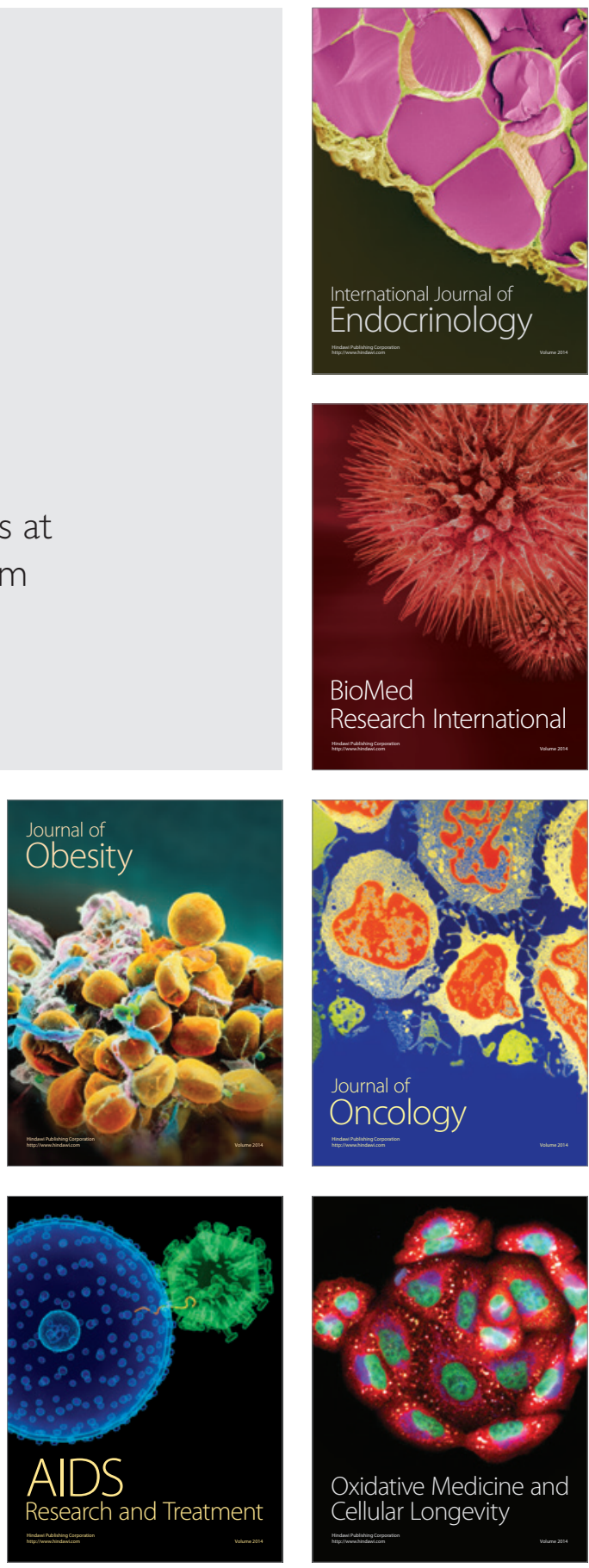